\title{
ĐÁNH GIÁ KÊT QUẢ ĐIỀU TR!̣ LASER NỘI TĨNH MẠCH TRONG BỆNH LÝ SUY GIÃN TĨNH MẠCH NÔNG CHI DƯớI TẠI BỆNH VIỆN TRUNG ƯƠNG HUÊ VỚI LASER BÁN DÃ̃N BƯớC SÓNG 1470NM
}

\author{
Nguyễn Thị Cẩm Vân*, Tôn Thất Thắng*, Đặng thị Thanh Vân* Phan Hà Thùy Trang*
}

\section{TÓM TẮT}

Mục tiêu: Đánh giá kết quả phương pháp điều trị laser nội tĩnh mạch để điều trị bệnh lý suy giãn tĩnh mạch

Đối tượng và phương pháp nghiên cứu: Nghiên cứu mô tả cắt ngang các bệnh nhân suy giãn tĩnh mạch nông chi dưới được chẩn đoán bằng siêu âm Doppler mạch máu.

Kết quả: Từ 11/2014 đến 12/2015 Có 72 trường hợp laser nội tĩnh mạch được chọn nghiên cứu độ tuổi từ $20-78$, tỉ lệ nữ / nam là 4/1, 71 trường hợp can thiệp trên tĩnh mạch hiển lớn chiếm tỉ lệ $98,6 \%$, chỉ có 1 trường hợp tĩnh mạch hiển bé $(1,4 \%)$. Đa số được thực hiện laser nội tĩnh mạch với bước sóng $1470 \mathrm{~nm}$, công suất $6-10 \mathrm{w}$. Có 4 trường hợp phải kết hợp với Muller và 8 trường hợp phối hợp tiêm xơ bọt. Phần lớn trường hợp gây tê tại chỗ chỉ có 4 trường hợp gây tê tủy sống ( $8 \%$ ). Kết quả bước đầu rất tốt, không có biến chứng trong quá trình thao tác. Đánh giá lâm sàng sau can thiệp đa số bệnh nhân không đau hoặc đau nhẹ không cần dùng thuốc giảm đau, một trường hợp đau nhiều cần phải dùng thuốc giảm đau mạnh khoảng 5 ngày. Siêu âm sau can thiệp 1 tuần: $100 \%$ trường hợp tĩnh mạch được can thiệp teo nhỏ và không có dòng chảy bên trong, không có huyết khối tĩnh mạch sâu và nông. Một số bệnh nhân tái khám sau 3 tháng, sau 6 tháng vẫn cho kết quả rất tốt hầu như không có tái phát.

Kết luận: Phương pháp laser nội tĩnh mạch trong điều trị suy giãn tĩnh mạch là phương pháp được ưa chuộng trong thập niên gần đây vì tính ưu việt như: ít xâm lấn, tỉ lệ thành công cao, ít biến chứng và có tính thẩm mỹ cao, nhanh chóng đưa người bệnh về cuộc sống thường nhật.

\section{EVALUATING THE RESULTS OF ENDOVENOUS LASER TREATMENT FOR LOWER LIMB VENOUS INSUFFICIENCY IN HUE CENTRAL HOSPITAL BY 1470NM DIODE LASER}

\section{SUMMARY}

Objective: to evaluate the result of endovenous laser treatment for venous insufficiency.
Trần Thanh Thái Nhân*, Trần Hoài Ân*

Methods: this is a cross-sectional study including the patient with venous insufficiency who underwent diagnose and treatment at hue central hospital

\section{Results:}

Lower limb venous insufficency (VI) is common. This disease is diagnosed by clinical symptoms and echodoppler. The surgical treatment remains a main method for this disease. Recently, there are many alternative methods for this disease such as sclerotherapy, radiofrequnce and laser ablation. Laser is one of effective methods for VI. Between december 2014 and november 2015, there were 72 patients with VI at stage C2-3 (CEAP classification) underwent endovenous laser ablation. Patients were from 20 to 78 years old with female and male ratio at $4 / 1$. Patients with internal saphenous insufficency were 98,6\% (71 cases) and only $1.4 \%$ with external saphenous diease. Most of them were treated with laser wavelength at $1470 \mathrm{~mm}$, power at $6-10 \mathrm{~W}$. There were 4 patients needed phlebectomy and 8 patients associated with sclerotherapy. Most of cases underwent local anesthesia, except for 4 patients needed spinal anesthesia (8\%).

The initial results were good, there were no complication related to the procedure. Most of patient were no pain after procedure. The number of patient with mild (no need of antalgics) and severe pain (needed fort antalgics for 5 days) after laser ablation were 4 cases and 1 case, respectively. 46 patients could return to daily activities at the day later.

Post procedure echography results at one week period: $100 \%$ of cases presented sclerosant veins and no intravenous flow, no deep venous thrombose. There were no recurrence at 3 and 6 month of medical revisit.

Conclusion: endovenous laser treatment is a method of preference for VI because of its advandtages such as miniinvasive technique, high successive percentage, minime complication, high aesthetics and early to return daily activities.

*Bệnh viện Trung Uong Huế

Người chịu trách nhiệm khoa họ: ThS. Trần Hoài Ân

Ngày nhận bài: 10/01/2016 - Ngày Cho Phép Đăng: 24/02/2016

Phản Biện Khoa học: PGS.TS. Đặng Ngọc Hùng

GS.TS. Lê Ngoc Thành 


\section{1. ĐẶT VẤN ĐỀ}

Suy giãn tĩnh mạch nông chi dưới là bệnh lý khá phổ biến. Chẩn đoán bệnh dựa vào các dấu chứng lâm sàng và siêu âm Doppler mạch máu. Trước đây phẫu thuật stripping gần như là lựa chọn duy nhất. Trong những năm gần đây, với sự tiến bộ của Y học có nhiều phương pháp điều trị như tiêm xơ bọt, sóng cao tầng và laser nội tĩnh mạch để điều trị bệnh lý này. Laser nội tĩnh mạch là một trong những phương pháp điều trị bệnh lý suy dãn tĩnh mạch nông chi dưới hiệu quả. Chúng tôi tiến hành nghiên cứu nhằm mục tiêu: Đánh giá kết quả phuoong pháp laser nội tĩnh mạch trong điều trị bệnh lý suy giãn tĩnh mạch

\section{2. ĐỐI TƯợNG VÀ PHƯƠNG PHÁP NGHIÊN CÚU}

\section{1. Đối tượng nghiên cứu}

Bao gồm 72 tĩnh mạch hiển được chẩn đoán suy dãn tĩnh mạch nông chi dưới nguyên phát điều trị nội trú tại bệnh viện Trung U’ơng Huế từ tháng 12/2014 đến $11 / 2015$.

\subsubsection{Tiêu chuẩn chọn bệnh:}

Các bệnh nhân được chẩn đoán suy giãn tĩnh mạch nông chi dưới nguyên phát qua siêu âm doppler mạch máu có đường kính tĩnh mạch từ $5 \mathrm{~mm}$ trở lên.

\subsubsection{Tiêu chuẩn loại trù̀:}

Các bệnh nhân được chẩn đoán suy giãn tĩnh mạch nông chi dưới kèm huyết khối tĩnh mạch, tĩnh mạch nông giãn kèm uốn lượn nhiều, bệnh dị dạng mạch máu, bệnh về máu, có thai.

\subsection{Phương pháp nghiên cứu:tiến cứu, theo dõi dọc theo thời gian 12 tháng.}

\subsubsection{Phương tiện nghiên cứu:}

Máy VenaCure 1470 Laser bước sóng 1470 nm; Máy siêu âm Zonnare; kim chụp mạch máu 18G, dây dẫn (Guide-wire) 0.035; ống dẫn (Sheath) 5F; dung dịch Lidocaine $0,25 \%$ (100 - 120ml). Dung dịch Lidocaine $1 \%$ để gây tê tại chỗ

\subsubsection{Các bước tiến hành}

- Khám lâm sàng và các xét nghiệm cơ bản.

- Siêu âm doppler mạch máu đánh giá đường kính tĩnh mạch nông, dòng phụt ngượt, các nhánh xuyên, các nhánh bên, các tĩnh mạch hệ sâu.
- Siêu âm vẽ đường đi tĩnh mạch và đánh dấu vị trí đâm kim.

- Laser nội tĩnh mạch qua da dưới hướng dẫn của siêu âm.

- Theo dõi bệnh nhân sau thủ thuật ghi nhận kết quả thủ thuật trong khoảng thời gian 12 tháng.

\subsection{Xử lí số liệu thống kê} 3. KẾT QUẢ

Từ tháng 12/2014 đến 11/2015 có 52 bệnh nhân suy giãn tĩnh mạch nông chi dưới nhập bệnh viện Trung Ương Huế để điều trị laser. Chúng tôi đã can thiệp laser nội tĩnh mạch trên 72 tĩnh mạch hiển

\section{1. Đặc điểm chung}

\begin{tabular}{|l|l|c|c|}
\hline \multicolumn{2}{|c|}{ Đặc điểm bệnh nhân } & Số lượng & Tỉ lệ \\
\hline \multicolumn{2}{|c|}{ Tuồi trung bình } & 58,4 & 12,1 \\
\hline \multirow{2}{*}{ Giới } & Nam & 11 & $21,1 \%$ \\
\cline { 2 - 4 } & Nữ & 41 & $78,9 \%$ \\
\hline $\begin{array}{l}\text { Số người } \\
\text { mắc bệnh }\end{array}$ & Ở một chi & 32 & $61,5 \%$ \\
\hline & Ở hai chi & 20 & $38,5 \%$ \\
\hline
\end{tabular}

3.2. Đặc điểm lâm sàng:

\begin{tabular}{|l|c|c|}
\hline \multicolumn{1}{|c|}{ Triệu chứng } & $\begin{array}{c}\text { Số } \\
\text { lượng }\end{array}$ & $\begin{array}{c}\text { Tỷ lệ } \\
(\%)\end{array}$ \\
\hline Đau chân & 53 & 73,6 \\
\hline $\begin{array}{l}\text { Nắng chân, cảm giác nặng trong } \\
\text { bắp chân }\end{array}$ & 72 & 100 \\
\hline Bị sưng chân, căng bắp chân & 46 & 63,9 \\
\hline Ngứa chân & 22 & 30,5 \\
\hline Cảm giác nóng rát ở bắp chân & 21 & 29,1 \\
\hline $\begin{array}{l}\text { Triệu chứng tăng lên khi đứng lâu } \\
\text { một chỗ bất động }\end{array}$ & 72 & 100 \\
\hline $\begin{array}{l}\text { Tĩnh mạch dãn nồi ngoằn ngoèo } \\
\text { trên chân }\end{array}$ & 72 & 100 \\
\hline Loạn dưỡng da vùng cố chân & 3 & 4,2 \\
\hline
\end{tabular}

3.3. Đặc điểm siêu âm doppler

3.3.1. Đường kính tĩnh mạch hiển

\begin{tabular}{|c|c|c|c|c|}
\hline \multirow{2}{*}{ Vị trí } & \multicolumn{2}{|c|}{$\begin{array}{c}\text { TMH có đk } \\
\text { từ } 5-10 \mathrm{~mm}\end{array}$} & \multicolumn{2}{|c|}{$\begin{array}{c}\text { TMH có } \\
\text { đường } \\
\text { kính }>10 \mathrm{~mm}\end{array}$} \\
\hline & $\begin{array}{c}\text { Số } \\
\text { lượng } \\
\text { (n) }\end{array}$ & $\begin{array}{l}\text { Tỉ lệ } \\
\text { (\%) }\end{array}$ & $\begin{array}{c}\text { Số } \\
\text { lượng } \\
\text { (n) }\end{array}$ & $\begin{array}{l}\text { Tỉ lệ } \\
\text { (\%) }\end{array}$ \\
\hline Chỗ nối hiển lớn - đùi & 60 & 83,3 & 12 & 16,7 \\
\hline Chỗ nối hiển bé - khoeo & 1 & 1,4 & 0 & 0 \\
\hline Đoạn trên gối $2 \mathrm{~cm}$ & 68 & 94,4 & 4 & 5,5 \\
\hline Đoạn dưới gối $2 \mathrm{~cm}$ & 72 & 100 & 1 & 1,4 \\
\hline Đoạn cẳng chân & 21 & 29,2 & 0 & 0 \\
\hline
\end{tabular}


3.3.2. Dòng chảy ngực: $100 \%$ có dòng chảy ngự̣c phân bố đều trên suốt đường đi của tĩnh mạch với thời gian hồi luu trên 1 giây

\subsection{3. Đặc điểm của các tĩnh mạch bên và tĩnh mạch xuyên}

\begin{tabular}{|l|c|c|c|c|c|c|}
\hline \multirow{2}{*}{ Đường kính tĩnh mạch } & \multicolumn{2}{|c|}{$<3 \mathrm{~mm}$} & \multicolumn{2}{c|}{$3-5 \mathrm{~mm}$} & \multicolumn{2}{c|}{$>5 \mathrm{~mm}$} \\
\cline { 2 - 7 } & $\mathrm{N}$ & Tỉ lệ (\%) & $\mathrm{N}$ & Tỉ lệ (\%) & $\mathrm{N}$ & Tỉ lệ (\%) \\
\hline Tĩnh mạch bên & 60 & 83,3 & 8 & 11,1 & 4 & 5,6 \\
\hline Tĩnh mạch xuyên & 65 & 90,3 & 3 & 0,13 & 4 & 5,6 \\
\hline
\end{tabular}

\subsection{Phân loại can thiệp}

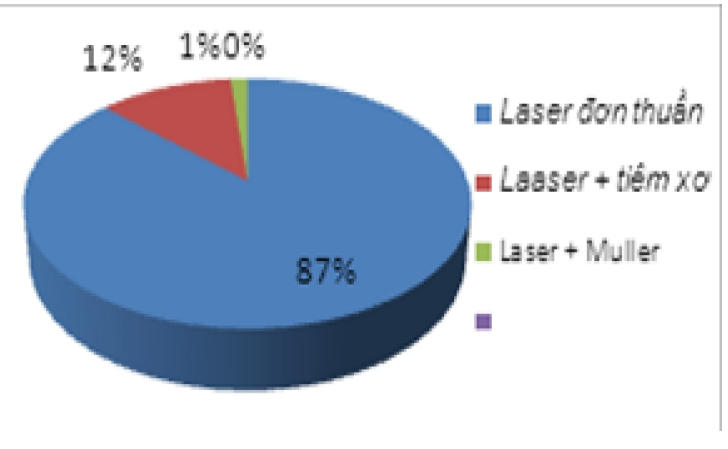

3.6. Phương pháp vô cảm

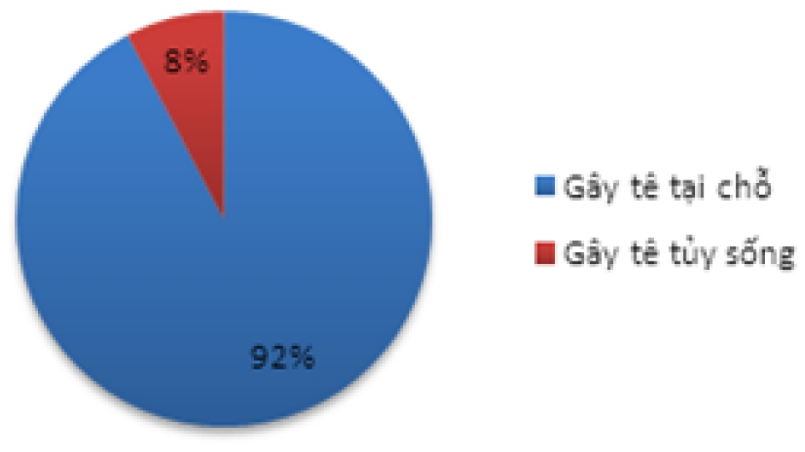

\subsection{Kết quả can thiệp:}

\subsubsection{Kết quả lâm sàng sau thủ thuật}

\begin{tabular}{|l|c|c|c|c|c|c|c|c|}
\hline \multirow{2}{*}{\multicolumn{1}{|c|}{ Đặc điểm }} & \multicolumn{3}{c|}{$\mathbf{1}$ tuần } & \multicolumn{2}{c|}{$\mathbf{1}$ tháng } & \multicolumn{2}{|c|}{3 tháng } & \multicolumn{2}{c|}{$>\mathbf{6}$ tháng } \\
\cline { 2 - 12 } & $\mathbf{N}$ & $\mathbf{\%}$ & $\mathbf{N}$ & $\mathbf{\%}$ & $\mathbf{N}$ & $\mathbf{\%}$ & $\mathbf{N}$ & $\mathbf{\%}$ \\
\hline Không đau chân hoặc đau nhẹ & 71 & 98,6 & 72 & 100 & 72 & 100 & 72 & 100 \\
\hline Cảm giác dễ chịu, không có dị cảm & 71 & 98,6 & 72 & 100 & 72 & 100 & 72 & 100 \\
\hline Vết thâm tím dọc theo thân tĩnh mạch & 3 & 4,1 & 0 & 0 & 0 & 0 & 0 & 0 \\
\hline Không còn tĩnh mạch dãn nồi rõ trên da & 0 & 0 & 0 & 0 & 2 & 2,8 & 1 & 1,4 \\
\hline Nhiễm trùng chỗ đâm kim & 0 & 0 & & & & & & \\
\hline
\end{tabular}


3.7.2. Kết quả siêu âm doppler sau thủ thuật

\begin{tabular}{|l|c|c|c|c|c|c|c|c|}
\hline \multicolumn{1}{|c|}{ Đặc điểm } & \multicolumn{2}{|c|}{$\mathbf{1}$ tuần } & \multicolumn{2}{c|}{$\mathbf{1}$ tháng } & \multicolumn{3}{|c|}{3 tháng } & \multicolumn{2}{c|}{$\mathbf{6}$ tháng } \\
\cline { 2 - 10 } & $\mathbf{N}$ & $\mathbf{\%}$ & $\mathbf{N}$ & $\mathbf{\%}$ & $\mathbf{N}$ & $\mathbf{\%}$ & $\mathbf{N}$ & $\mathbf{\%}$ \\
\hline Thân tĩnh mạch được làm laser teo nhỏ & 72 & 100 & 72 & 100 & 72 & 100 & 72 & 100 \\
\hline $\begin{array}{l}\text { Không còn tồn tại dòng chảy bên trong thân tĩnh } \\
\text { mạch được làm laser }\end{array}$ & 72 & 100 & 72 & 100 & 72 & 100 & 72 & 100 \\
\hline Huyết khối tĩnh mạch sâu & 0 & 0 & 0 & 0 & 0 & 0 & 0 & 0 \\
\hline Huyết khối tĩnh mạch nông & 0 & 0 & 0 & 0 & 0 & 0 & 0 & 0 \\
\hline Tụ máu quanh thân thĩnh mạch & 3 & 4,1 & 0 & 0 & 0 & 0 & 0 & 0 \\
\hline Giãn tĩnh mạch vùng cẳng chân tái phát & 0 & 0 & 0 & 0 & 2 & 2,8 & 1 & 1,4 \\
\hline
\end{tabular}

\subsubsection{Thòi gian nằm viện}

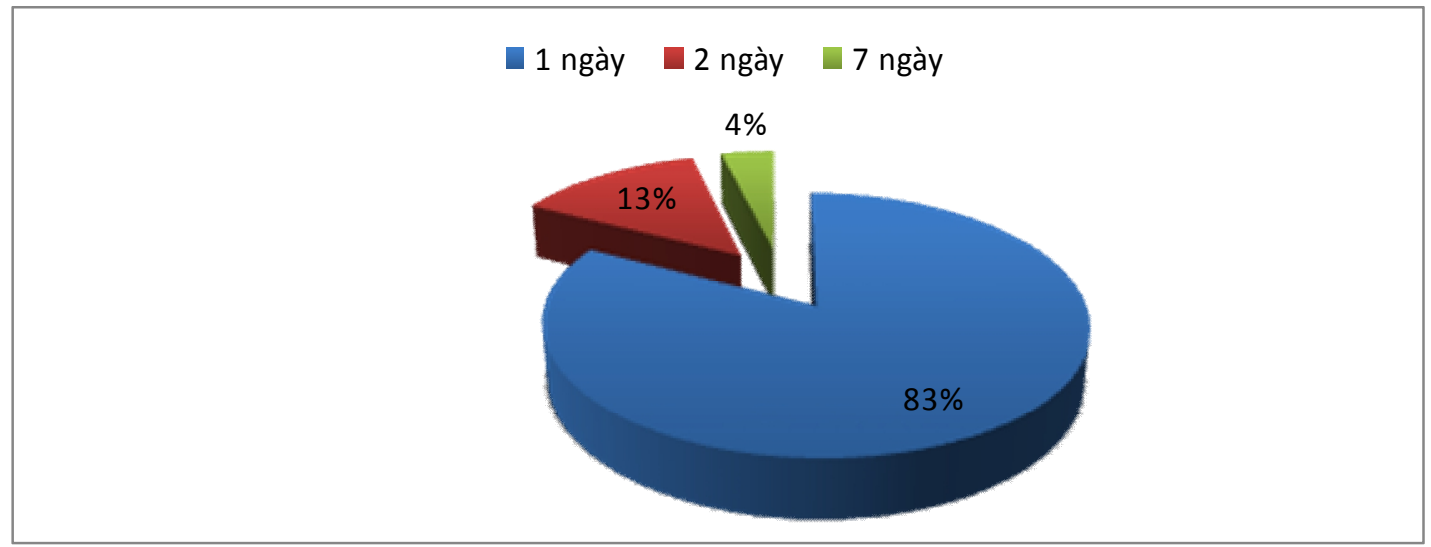

Kết quả bước đầu rất tốt, không có biến chứng trong quá trình can thiệp. Đa số bệnh nhân không có cảm giác đau hoặc chỉ đau nhẹ sau can thiệp mà không cần dùng thuốc giảm đau. Tuy nhiên chỉ có một bệnh nhân đau nhiều cần phải uống giảm đau sau can thiệp 5 ngày. Siêu âm doppler hầu hết các tĩnh mạch được can thiệp đều teo nhỏ, hòan toàn không có dòng chảy bên trong, không có huyết khối tĩnh mạch sâu và nông. Theo dõi sau điều trị suốt 12 thángvẫn cho kết quả rất tốt hầu như không có tái phát.

\section{BÀN LUẬN}

Bệnh lý suy giãn tĩnh mạch nông chi dưới được biết từ thời Hippocrates (khoảng $460-377 \mathrm{BC}$ ), trải qua nhiều thế kỷ có nhiều khám phá mới về bệnh học, sinh lý bệnh, chẩn đoán và phương pháp điều trị. Bệnh thường gặp ở hầu hết các nước trên thế giới, tỉ lệ nữ mắc bệnh nhiều hơn nam. Theo nghiên cứu của của giáo sư Văn Tần (1998) tỉ lệ mắc bệnh suy tĩnh mạch mạn tính là $43,97 \%$ ở bệnh nhân trên 50 tuổi, tại thành phố Hồ Chí Minh và nghiên cứu chúng tôi độ tuổi mắc bệnh trung bình là 58,4 +/- 12,1.
Hiện nay, Siêu âm Doppler đã trở thành phương pháp đượcchọn lựa và được xem là tiêu chuẩn vàng trong chẩn đoán bệnh suy dãn tĩnh mạch [12].

Phương pháp điều trị kinh điển là phẫu thuật stripping loại bỏ thân tĩnh mạch hiển. Phương pháp phẫu thuật cho kết quả tốt. Nhưng có nhiều hạn chế như sau: sử dụng phương pháp vô cảm bằng gây tê tủy sống hoặc gây mê toàn thân, thời gian nằm viện kéo dài, thời gian hồi phục để lao động kéo dài, có tỉ lệ nhiễm trùng vết mổ, đau và dị cảm sau mổ và tính thẩm mỹ không cao. 
Từ cuối thập niên 80 - 90, nhiều phương pháp điều trị mới ít xâm lấn, ít đau, ít biến chứng, thời gian hồi phục nhanh bắt đầu được báo cáo trong điều trị bệnh lý suy giãn tĩnh mạch nông chi dưới. Đó là các phương pháp can thiệp nội tĩnh mạch: tia laser nội mạch, sóng cao tần nội mạch, tiêm xơ bọt. Các phương pháp này hiệu quả, an toàn được áp dụng ngày càng nhiều trên thế giới.

Đến năm 1999, Bone người Tây Ban Nha đã thực hiện trường hợp laser nội mạch đầu tiên, sau đó là Mỹ (năm 2000) và Pháp (năm 2002). Đây là phương pháp mới, ít xâm lấn, thời gian thực hiện và hồi phục nhanh, đặc biệt là tính thẩm mỹ rất cao. Từ đó đến nay, phương pháp này đã được thực hiện trên nhiều nước trên thế giới.

Thành phố Hồ Chí Minh thực hiện phương pháp này vào năm 2008 với tỉ lệ thành công cao 97 - 98\% và ít tai biến.

Tại Bệnh viện Trung Ương Huế chúng tôi đã thực hiện trường hợp laser nội mạch đầu tiên vào năm 2005 tại Hội thảo quốc tế Việt - Pháp lần thứ 3 về bệnh lý tim mạch nội ngoại khoa. Mười năm sau, chúng tôi mới được trang bị máy móc và tháng 12/2014 phương pháp này mới được đưa vào thực hiện một cách thường qui với kết quả ban đầu rất tốt, chưa thấy tai biến. Tính đến nay chúng tôi đã thực hiện khoảng 52 bệnh nhân với 72 chân được điều trị laser nội tĩnh mạch tỉ lệ thành công $100 \%$. Các bước sóng laser có thể sử dụng được là $810 \mathrm{~nm}, 940 \mathrm{~nm}, 980 \mathrm{~nm}, 1470 \mathrm{~nm}$. Trong đó bước sóng $810 \mathrm{~nm}$ được sử dụng phổ biến nhất [5]. Trung tâm Y khoa MEDIC thành phố Hồ Chí Minh đã sử dụng laser bước sóng 810nm [2], tại bệnh viện Trung Ương Huế chúng tôi đã thực hiện với máy laser VENACURE bước sóng 1470nm.

Trên thế giới nhiều báo cáo khoa học đánh giá hiệu quả của laser nội tĩnh mạch trong điều trị bệnh lý suy dãn tĩnh mạch nông mạn tính ở nhiều thời điểm khác nhau đều cho thấy tỉ lệ thành công khá cao. Năm 2001 tại Mỹ hai nghiên cứu của Min và Navarro tỉ lệ thành công sau 6 tháng là $96 \%$ và $100 \%$ [8][9]. Theo nghiên cứu của các tác giả người Pháp, tỉ lệ thành công của Gerard sau 1 tháng là $100 \%$ và Sadick sau 2 năm là 97\% [4]
Ở Việt Nam, theo nghiên cứu của chúng tôi cho thấy $100 \%$ có kết quả tốt trên siêu âm cũng phù hợp với tác giả Hồ Khánh Đức thành phố Hồ Chí Minh. [2]

Việc lựa chọn phương pháp can thiệp phối hợp chúng tôi dựa vào đặc điểm và số lượng các tĩnh mạch xuyên và các tĩnh mạch bên. Nếu các tĩnh mạch xuyên và bên có đường kính lớn hơn $5 \mathrm{~mm}$, có suy van tĩnh mạch thì sau khi laser thân tĩnh mạch chúng tôi rút bỏ tĩnh mạch bằng Muller (đường rạch da nhỏ), có 8 trường hợp đường kính tĩnh mạch bên từ $3-5 \mathrm{~mm}$ chúng tôi tiến hành tiêm xơ bọt phối hợp cho kết quả tốt sau 1 tháng còn các trường hợp còn lại (đường kính $<3 \mathrm{~mm}$ ) tự teo nhỏ sau laser thân tĩnh mạch. Nhờ sự chọn lựa phương pháp điều trị phối hợp tốt nên kết quả can thiệp của chúng tôi rất khả quan.

Xác định vị trí đâm kim cũng cần đưa ra để bàn luận. Chúng tôi có 3 nhóm bệnh nhân: nhóm chọn vị trí đâm kim ở trên gối $2 \mathrm{~cm}$, nhóm hai chọn dưới gối $2 \mathrm{~cm}$ và nhóm 3 vị trí đâm kim ở vùng cẳng chân (cách mắc cá trong $10 \mathrm{~cm}$ ). Ở nhóm 1 có 2 trường hợp phải làm laser nội tĩnh mạch lần hai trên đoạn thân tĩnh mạch chưa được làm laser vùng cẳng chân sau 3 tháng và 10 tháng. Nhóm 3 cho kết quả tốt nhất các nhánh tĩnh mạch xuyên và bên xẹp hoàn toàn sau thủ thuật,phần nào hạn chế thủ thuật phối hợp như thắt tĩnh mạch xuyên hay Muller bóc tĩnh mạch. Tuy nhiên, sự chọn lựa vị trí đâm kim ở vùng cẳng chân còn tùy thuộc nhiều yếu tố như đường kính tĩnh mạch tại vị trí đâm kim, độ uốn lượn của tĩnh mạch, bề dày mô mỡ dưới da (từ tĩnh mạch đến da)...Do đó nếu chọn lựa vị trí đâm kim tốt thì sự can thiệp rất thuận lợi và trở nên đơn giản.

Biến chứng xảy ra trong và sau thủ thuật là rất hiếm. Hầu hết chúng tôi gây tê tại chỗ nên hạn chế được các biến chứng do gây mê hay gây tê tủy sống. Trong quá trình thủ thuật bệnh nhân không đau là do chúng tôi tiêm dung dịch thuốc tê xung quanh thân tĩnh mạch dưới hướng dẫn của siêu âm.

Kenneth Myer báo cáo trên 404 tĩnh mạch hiển được làm laser nội tĩnh mạch có hai trường hợp huyết khối tĩnh mạch sâu và 1 trường hợp thuyên tắc phổi. [5] Các nghiên cứu khác tỉ lệ này < 1\% [6]. Người ta cho rằng biến chứng huyết khối tĩnh mạch sâu chỉ xảy ra khi 
đầu dây laser đặt sai vị trí đi vào tĩnh mạch sâu [8]. Theo nghiên cứu của chúng tôi chưa thấy trường hợp nào có biến chứng này.

Cũng như các nghiên cứu khác chúng tôi không có biến chứng bỏng, dị cảm ở da và nhiễm trùng ở vị trí đâm kim.

Một số nghiên cứu trước đây có đề chúng tôi vẫn cập đến vấn đề bỏng do can thiệp nhưng với chúng tôi chưa thấy có trường hợp nào có thể do chúng tôi sử dụng máy với bước sóng cao $1470 \mathrm{~nm}$ nên ít thương tổn đến các mô xung quanh.

Về biến chứng thương tổn mạch máu, thuyên tắc tĩnh mạch sâu hoặc gây tê quanh tĩnh mạch chúng tôi kiểm soát được do quá trình làm đều dưới sự hướng dẫn của siêu âm

Hầu hết trường hợp nghiên cứu bệnh nhân đều có thể vận động được ngay sau khi can thiệp, thời gian nằm viện ngắn bệnh nhân có thể đi làm việc trở lại ngay ngày hôm sau.

Đặc biệt, bộ dụng cụvà sợi dây phát tia laser chúng tôi có thể tái sử dụng sau khi cắt phần đã bị đốt cháy đi bằng dao đặc chủng (được làm bằng kim cương) sau đó đem tiệt trùng bằng phương pháp plasma nên giá thành điều trị giảm nhiều so với những nơi khác.

\section{KẾT LUẬN}

Phương pháp laser nội tĩnh mạch đã và đang là hướng đi mới trong điều trị suy giãn tĩnh mạch nông chi dưới. Chúng tôi nhận thấy đây là phương pháp điều trị ít xâm lấn, ít biến chứng và đặc biệt là tỉ lệ thành công cao. Uu điểm của phương pháp này là có thể điều trị ngoại trú, tĩnh thẫm mỹ cao, thời gian hồi phục nhanh và với những cải tiến của chúng tôi đã làm giá thành điều trị xuống mức thấp nhất có thể.

\section{TÀI LIỆ THAM KHẢO}

1. Bộ môn ngoại, Phân môn ngoại lồng ngực-tim mạch Trường đại học $\mathrm{Y}$ Dược Thành phố Hồ Chí Minh (2008), "Suy tĩnh mạch nông chi dưới mạn tính", Điều trị học ngoại khoa lồng ngục-tim mạch, Nhà xuất bản Y học, Thành phố Hồ Chí Minh, tr. 72-84.
2. Hồ Khánh Đức (2010), Điều trị suy tĩnh mạch nông chi dưới bằng phương pháp laser nội tĩnh mạch với laser bán dẫn bước sóng 810nm, tạp chí Y học Việt Nam, Tổng hội Y học Việt Nam, Tr.315-322.

3. Nguyễn Phước Bảo Quân (2012), "Phân tích thông tin trong siêu âm Doppler tĩnh mạch", Siêu âm Doppler mạch máu, Nhà xuất bản Đại học Huế, tr. 156-170.

4. Gerard JL, Desgranges P, Becquemine J. Feasibility of endovenous laser fort the treatment of greater saphenous varicose veins: one month outcome in a series of 20 outpatients. J Mal Vasc 2002;27:222-5

5. Kenneth Myers, Rokert fris and Damien Jolley. Treatment of varicose veins by endovenous laser therapy: assessment of results by ultrasound surveillance, MJA 2006; 185 (4): 199-202.

6. Mark H, Meissner, Pannier F. Primary chronic venous disorders. J Vasc sur 2007;46:54s-65s.

7. Meissner M.H. et al (2007), "The hemodynamic and diagnosis of venous disease", J Vasc Surg, 46(S), pp. 4S-24S.

8. Min $\mathrm{R}$, Zimmet $\mathrm{S}$, Isaacs $\mathrm{M}$, Forrestal $\mathrm{M}$. Endovenous laser treatment of the incompetent greater saphenous vein. J Vasc Interv Radiol 2001; vol $121167-71$

9. Navarro L, Min R, Bone C. Endovenous laser: a new minimally invasive method of treatment for varicose veins - preliminary observation using an 810nm diode laser. Dermatol Surg 2001; 27: 117-22

10. Pannier F, Rabe E. Mid-term results following endovenous laser abation of saphenous veins with a 980nm diode laser. International Angiology - vol 27-12/200, p $475-481$.

11. Thrush A., Hartshorne T. et al (2005), “Anatomy of the limb venous system and assessment of venous insufficiency", Peripheral Vascular Ultrasound-How, When and Why, 2nd Edition, Elsevier, pp.163-188.

12. Zygmunt J.Jr. (2009), "What is new in duplex scanning of venous system",Perspect Vasc Surg Endovasc Ther, 21(2), pp. 94-104. 